\title{
Desejo e autoridade em Deleuze e Guattari ${ }^{1}$
}

Zamara Araujo*

RESUMO: O presente artigo tem como objetivo apresentar a relação entre desejo e autoridade em Deleuze e Guattari. Trata-se, em primeiro lugar, de elucidar a concepção do desejo como construção de agenciamentos, que, situada na perspectiva do capitalismo, constitui o regime de produção e efetuações de uma máquina desejante. Em um segundo momento, procuramos analisar o tema da autoridade à luz da reflexão sobre a instituição e a lei, e seus desdobramentos para o campo de efetuação do desejo.

PALAVRAS-CHAVE: Desejo, Agenciamento, Máquina-desejante, Autoridade, Lei.

\section{Desire and authority in Deleuze and Guattari}

\begin{abstract}
This article aims to present the relationship between desire and authority in Deleuze and Guattari. Firstly, it is a question of elucidating the concept of desire as a construction of agency, which, situated from the perspective of capitalism, constitutes the regime of production and effectuation of a desiring machine. In a second moment, we seek to analyze the theme of authority in the light of the reflection on the institution and the law, and their consequences for the field of effectuation of desire.
\end{abstract}

KEYWORDS: Desire, Agency, Desiring Machine, Authority, Law.

\section{Désir et autorité chez Deleuze et Guattari}

RÉSUMÉ : Cet article vise à présenter la relation entre le désir et l'autorité chez Deleuze et Guattari. Il s'agit, d'abord, d'élucider la conception du désir comme construction de l'agencement, qui, située du point de vue du capitalisme, constitue le régime de production et de réalisation d'une machine désirante. Dans un second temps, nous cherchons à analyser le thème de l'autorité à la lumière de la réflexion sur l'institution et le droit, et leurs conséquences pour le champ de la réalisation du désire.

MOTS-CLÉS : Désir, agencement, machine désirante, autorité, droit.

\footnotetext{
${ }^{1}$ Este artigo é uma versão revisada e ampliada de apresentação feita no "Colóquio Internacional Autoridade: dimensões clínicas, políticas e educacionais”, realizado em abril de 2019, na UFF. Agradeço a Prof ${ }^{a}$ Marília Etienne Arreguy (UFF) organizadora do Colóquio e deste Dossiê, pelo convite e oportunidade. O presente texto contorna o escopo das pesquisas desenvolvidas durante meu doutorado e pós-doutorado, recuperando algumas análises contextualizadas e revisadas de minha tese de doutorado.

* Doutora em Filosofia pela UNICAMP e PARIS X. Professora Titular de Filosofia da UESB.

E-mail: zamaraa@hotmail.com
} 
O conceito de desejo em Deleuze e Guattari demarca uma dimensão imanente e ativa inerente à economia dos afetos e seu caráter plural, permeando assim um horizonte e deslocamentos que subvertem teorias dominantes no sentido em que, ao trafegar fora dos cânones e estruturas hegemônicas descortina o liame de relações e múltiplas possibilidades concedidas às esferas do desejo e do inconsciente. Em entrevista à Claire Parnet, em 1988, por ocasião do seu L'abécédairé2, Deleuze define o desejo como construção de agenciamentos e adverte que desejar não é submeter-se a um fim como limite, mas invocar uma coletividade, pois os coletivos "nunca desejam alguém ou algo, desejam sempre um conjunto". Desejamos não alguma coisa, objeto ou alguém de forma isolada, mas um conjunto ou contexto que a faz existir como uma paisagem. Nesse sentido, "não há desejo que não corra para um agenciamento", “desejar é construir um agenciamento" (DELEUZE/PARNET, 1988).

Evidencia-se, com efeito, a inexistência do nexo estabelecido entre causa e efeito sublimado pela sustentação e crença de uma causalidade entre as coisas à espreita de um fim a ser realizado, ou um telos objetificado como limite regendo a submissão do desejo e dos afetos a uma configuração teleológica da vida e do pensamento. Não se trata de buscar um objeto de realização ou satisfação, não é algo que o desejo quer nem é sobre algo que ele se refere, pois o desejo não está subordinado a nada, tampouco se toma o desejo em função de um objeto do desejo, uma coisa ou alguém. O desejo invoca uma multiplicidade, uma força ativa e imanente que se refere a uma totalidade, um conjunto porque ele pressupõe um contexto, uma ambiência e um entorno que circunda as relações e suas linhas de vizinhança como uma paisagem. Há, portanto, uma geografia do desejo, ele está sempre em conexão com o entorno, com o acontecimento, com a paisagem que lhe confere sentido e constitui territorialidades. Desejar é uma arte construtivista de compor afetos e encontros, constituir regiões e territórios, é construir um agenciamento, é agenciar-se contornando um construtivismo incessante.

No contexto do L'Anti-QEdipe (1972), Deleuze e Guattari concebem uma nova concepção de desejo desvinculada das interpretações hegemônicas cunhada pela psicanálise e o estruturalismo. Perfilando a linha de confronto que estabelecem, visam considerar as reais condições e flutuação do desejo fora do campo de subtrações e coordenadas fixas, seja do estruturalismo ou da psicanálise. De um lado, o estruturalismo supõe um processo de organização e distribuição das relações e dos afetos segundo um vetor de distribuição sedimentada, fixa e homogênea, organizada de modo hierárquico e estrutural. De outro, a psicanálise, ao definir os afetos por um elemento extrínseco, promove a subordinação do desejo ao princípio da falta como determinação passiva do desejo e de suas realizações. Contra isso, Deleuze e Guattari desenvolvem uma clínica dos investimentos sócio-históricos, espécie de "geoanálise" dos modos de articulação entre os processos de subjetivação e os aparelhos institucionais. Desprezando

\footnotetext{
${ }^{2}$ L'abécédaire de Gilles Deleure, entrevista a Claire Parnet realizada em 1988, filmada e dirigida por Pierre-André Boutang, e publicada em vídeo em 1996.
} 
o modelo estruturalista e o princípio da "falta" sustentado pela psicanálise, o desejo e o delírio são situados ao nível dos investimentos sócio-históricos assinalando assim o domínio de uma esquizoanálise.

Para os autores de Capitalisme et schizophrénie é necessário abjurar ao universalismo do sujeito e a transcendência para então reconhecer e situar os desdobramentos do regime de produção capitalista às condições de produção do desejo e do inconsciente. No âmbito dessa complexidade e jogo intricado de relações, o complexo de Édipo sustentado na filiação familiar e natural não abarca o caráter transitório e contingente da dinâmica real das alianças e filiações, pois esta corresponde menos à estrutura familiar formal do que ao campo móvel e social das relações econômicas, cujos investimentos no campo social e cultural escapam às estruturas e modelos da história. O que há é um processo que envia as relações que se movem não segundo uma lei necessária ou uma ordem contínua e estável, mas que se revela consoante às conexões extrínsecas, às determinações contingentes e descontínuas.

Visando a redefinir a noção de inconsciente longe da visão edipiana do vivido e do desejo, Deleuze e Guattari conferem ao desejo um princípio imanente, definindo um plano de consistência que se constitui como uma interação operante de instantes, circunstâncias, experiências e acontecimentos. O plano da natureza não supõe um princípio transcendente representado como símbolo ou arquétipo da cultura passada, que resultaria numa significação idealista do vivido e do desejo. Ele implica um plano de imanência constituído como processo de produção, produção maquínica de forças, instantes e acontecimentos advindos do vínculo entre desejo e devir, e desse modo, concernem às ligações e operações de uma máquina desejante, produtora e reprodutora que atua no limite do capitalismo. Desse modo, não se pode desvincular o desejo do regime de signos e investimentos sociais, tal como as circunstâncias de sua produção, tendo como princípio imanente a produção capitalista; o capitalismo constitui o limite, sendo este limite definido pela relação entre desejo e esquizofrenia, e "sendo a esquizofrenia identificada ao processo primário do desejo” (SIBERTIN BLANC, 2010, 56).

Considerando o desejo como dimensão ativa e imanente, Deleuze e Guattari se separam da representação edipiana do desejo baseado na falta e na culpa, sustentada pela psicanálise, dissociando o desejo do campo de representações que lhe conferem uma condição passiva e inerte. O desejo não remete à suposição de um do objeto (a possuir) ou de sujeito (ausente), nem se manifesta como afecção ou tensão de um sujeito em relação a um objeto, pois ao contrário, ele precede a fórmula dualista sujeito-objeto. O ponto de discórdia reside no fato de que, considerado sob uma lógica idealista, o desejo implicaria numa subordinação a um fim que se encontraria fora dele, figurando como causalidade ou finalidade que se explica pelo desejo de possessão e de onde ele seria sentido como falta, condição passiva definida pela carência ou pela posse.

Assim, com a noção de máquinas desejantes Deleuze e Guattari superam, duplamente, a ideia de uma subjetividade autômata centrada no Eu, e a concepção psicanalítica de desejo como falta ou recalque, encontrando na interpretação e releitura marxista o aporte necessário à noção de sujeito como produção, cujo processo implica um investimento social do desejo. Com efeito, as máquinas desejantes não operam 
de forma homogênea ou linear, elas só funcionam avariadas e são tomadas por uma desterritorialização contínua, por devires e linhas de fuga, mas também por fluxo e captura. O desejo invoca um campo de investimento social, instância maquínica que investe nas máquinas sociais. O desejo produz o real, ele é atividade e produção, experimentação incessante (sem sujeito), como investimento e criação do real, e disso se segue o limite que se estabelece face ao capitalismo sendo esse limite definido pela esquizofrenia. Como assevera Sibertin Blanc, "o que se indica do processo primário do desejo na enunciação esquizofrênica revela a posição limite que ocupa esse processo mesmo em relação aos códigos sociais” (SIBERTIN BLANC, 2010, 60). A esquizofrenia constitui uma saída, uma evasão, como ápice, da violência do capitalismo, de sua face cruel e sua prática selvagem, cujo limite é conduzido ao paroxismo.

Todo socius trata de ordenar e fixar o desejo e seus fluxos, registrando, marcando e esculpindo-os de forma que nenhum fluxo corra para fora sem antes ser canalizado e regularizado; dedica-se a codificar os fluxos do desejo para moldá-lo, normatizá-lo. A máquina capitalista opera a descodificação e desterritorialização dos fluxos, e atua sobre os vestígios de ruínas de uma soberania primitiva, uma violência remota, e disso se retroalimenta encontrando aí toda a condição e materialidade; logo, não há relação de exterioridade ou transcendência, pois são tais condições que lhe confere um caráter imanente. Disse deriva que o capitalismo se mostra "incapaz de fornecer um código" que abarque a totalidade do campo social, e "tende a limiar de descodificação que desfaz o sosius em proveito de um corpo sem órgãos e que libera, sobre este corpo, os fluxos do desejo num campo desterritorializado", e nesse processo, ele não cessa de se dirigir ao seu limite, cujo caráter é esquizofrênico (DELEUZE/GUATTARI, 1972, p.52).

Configurando-se como imanente e atuando sobre os fluxos, o capitalismo descodifica os códigos continuamente e paradoxalmente opera um sistema axiomático que não cessa de produzir, como investimento maquínico e produção maquínica, sem limites, de forma descentrada, recodificando os fluxos infinitamente. "O desejo é máquina”, asseveram Deleuze e Guattari, é produção maquínica infinita, sem sujeito ou objeto e nesse sentido, circunscreve um duplo aspecto: primeiro, a recusa e superação da fórmula psicanalítica do sonho e da fantasia como elemento dominante do inconsciente, sua dimensão reguladora entendida como lugar de extravasamento; segundo, ao invés de traduzir uma relação de correspondência ou adequação com o marxismo, o que se realiza é da ordem de uma torção que subverte os "modos de produção" inserindo uma linha afetiva circunstanciada por devir e fluxo. Situando o problema da "produção da existência" no plano do desejo, faz do desejo um elemento da infraestrutura (DELEUZE/GUATTARI, 1972, p.124). Sob esse traçado, o que se constitui é a afirmação de um "inconsciente fábrica" que rivaliza com a visão idealista do desejo definida como representação (do sonho), modelo de um “inconsciente-teatro”. Logo, a visão passiva do inconsciente-teatro é substituída pela dimensão ativa de um inconsciente-fábrica.

Em entrevista de 1972, Deleuze e Guattari explicam: "Máquina desejante é um sistema nãoorgânico do corpo", tratar-se-á de "máquina molecular ou micromáquinas", e o que criticamos na 
psicanálise é o fato dela não compreender que “o delírio é o investimento de um campo social”; e que o desejo é fábrica e não um teatro. "O que nos interessa é a presença das máquinas de desejo, micromáquinas moleculares, nas grandes máquinas sociais molares. De que modo agem e funcionam umas nas outras" (DELEUZE, 2006, p. 281)³. Portanto, no plano das máquinas desejantes, a subjetividade encontra seu significado no campo social como produção maquínica, efeito de uma máquina significante.

Substituindo a estrutura por uma esfera maquínica, o significante implica uma força maquinante que age sobre o indivíduo, moldando-o, territorializando e desterritorializando. Nesse caso, delineando composição de forças múltiplas e divergentes em que imperam rupturas, deslocamentos, o significante é atravessado por linhas transversais que se cortam e lhe conferem um sentido heterogêneo que, não reconhecendo mais nenhuma origem, destaca-se por seu efeito maquínico. O desejo não preexiste ao seu campo de produção e funcionamento, ele nasce de um fora, de um encontro, de um acontecimento e experimentação, expressão de composição maquínica, sistema corte-fluxo que envolve relação, afetos e devir.

O ponto de curvatura dessa teia de conexões reside no caráter sinuoso que prefigura entre os estratos, a linha molar e sua composição no campo da instituição. É precisamente na esteira das análises do primeiro volume de Capitalisme et schizophrénie (1972), L'Anti-CEdipe, que vemos descortinar um emaranhado complexo de relações múltiplas e reversibilidade, de modo que, não se pode requerer uma limitação do humano em face das declinações da instituição sobre o instinto, pois há sempre uma relação que se efetua por transporte e captura pela ação de uma instância extrínseca que opera de forma maquínica. Considerada por essa via a instituição é o lugar da experimentação e da conexão com o fora e, sendo assim, o sistema de modelos e meios sociais que integram a instituição pertence a um plano de relações, investimentos e domínio maquínico que invoca um campo afetivo determinado pelo desejo. Sob esse contexto, a instituição assinala o plano de organização que configura o nível molar, os grandes conjuntos molares constituído pelos estratos e segmentos que figuram sobre um meio determinado. De modo complementar, sua determinação não escapa aos meandros de movimentos moleculares que agem sobre os estratos, com suas linhas de fuga e de desterritorialização, e nesse sentido, a instituição congrega conjuntos e relações molares que repousam em conexões e devires moleculares.

Notadamente, os meandros desse quadro de conjugações e produção imanente se constituem por relações heterogêneas e reversibilidades, marcado por uma exterioridade em que, remontando ao percurso traçado por Hume, as relações são exteriores aos seus termos. Seguindo o rastro do empirismo humeano, Deleuze avalia nas teses de Empirisme et subjectivité (1953) que o autor inglês ultrapassa o dualismo metafísico quando este reivindica a oposição entre o homem e o animal e cujo liame fica às expensas de uma mediação da representação e da lei. Circunscrevendo uma dimensão ativa, o vínculo

${ }^{3}$ Cf. "Deleuze e Guattari explicam-se", entrevista publicada na coletânea $A$ ilha deserta. 
entre natureza e sociedade passa a constituir uma associação que enquanto tal subverte a condição do acordo e da atribuição extrínseca da lei e do contrato e passa então a ser considerada em torno da relação entre necessidade, tendência e instituição. Sob olhar de Hume, natureza e cultura formam um agregado complexo cuja configuração invoca o nexo entre a tendência e a instituição, pois "a natureza só atinge seus fins por meio da cultura; a tendência só se satisfaz através da instituição" (DELEUZE, 2001, 41). Este será o mote, portanto, das análises de um pequeno intitulado Instincts et institutions (1955), a saber, investigar de que maneira se efetua o vínculo entre a natureza e a cultura, o instinto e a instituição.

Deleuze intenta situar o ponto de convergência desse vínculo considerando um duplo movimento. De um lado, reagindo a estímulos externos, o organismo extrai (captura) do mundo exterior os elementos necessários à satisfação de suas tendências ou necessidades seguindo um impulso natural de onde ele criará um meio específico. De outro, instituindo um mundo entre suas tendências e o mundo exterior, a instituição elabora e organiza meios artificiais de satisfação que libera o organismo da natureza e o submete a outra coisa, modificando, assim, a tendência e instituindo um novo meio. Há, portanto, meios específicos originados de uma extração, e meios artificiais que derivam de uma elaboração. Todavia, o instinto, por encontrar em si próprio a satisfação de suas necessidades obtém os meios de sua satisfação de forma direta, sem intermediação nem coerção. A instituição, por sua vez, se caracteriza pelo fato de que os meios de satisfação de que se vale não se determina pela própria tendência, mas de circunstâncias exteriores a ela; ela se vale de recursos e meios de satisfação cuja aquisição se realiza de forma oblíqua, inventada e cultural. Logo, esses meios não derivam de condições internas ou naturais, mas emanam de um artifício, de um elemento exterior, e, assim, indireto.

O que ocorre nessa passagem é da ordem de uma experiência e de uma subversão que envolve o instinto, a instituição e o meio. No que concerne ao meio, ele é o elemento que preexiste à experiência e no qual ela é referida, orientada e organizada. Deve-se considerar então que toda experiência supõe, $a$ priori, "a preexistência de um meio no qual a experiência é levada a cabo, meio específico ou meio institucional. O instinto e a instituição são as duas formas organizadas de uma satisfação possível" (DELEUZE, 2006, 29). O meio e a exterioridade que o constitui designam o princípio de uma subversão que transforma o instinto dotando-lhe de uma dimensão, uma força, em vista da qual sua natureza é modificada. É sob essa configuração que a clivagem entre natureza e sociedade se converterá num campo de sutura cuja configuração remete a apropriações e relação de forças.

A instituição arrasta o instinto a condições outras ainda por se constituir, subvertendo a tendência e as relações com o meio. Portanto, no âmbito dessa subversão, verifica-se uma declinação da instituição sobre a tendência, o instinto, pois, embora o objetivo seja a satisfação da tendência, paradoxalmente os processos de satisfação que a instituição promove se desenvolve num embate à revelia da própria tendência. Nesse sentido, se a satisfação se dá de forma "oblíqua" e indireta no âmbito da instituição é porque implica relação de força, jogo de poder e coerção mediante a qual a tendência é constrangida, 
submetida a uma outra coisa, a uma força segundo a qual a tendência é requerida, capturada, e assim transformada.

A subversão que se opera no âmbito dessa transformação é decorrente dos agenciamentos que se configuram, dos acoplamentos e rupturas que se evidenciam nas dimensões molares e moleculares. De acordo com Zourabichvili, "se a instituição é um agenciamento molar que repousa em agenciamentos moleculares", tais como "a soma dos gestos, atitudes, procedimentos, regras, disposições espaciais e temporais que fazem a consistência concreta ou a duração", podemos então afirmar que o campo do desejo se reporta a esses agenciamentos, e sob essas circunstâncias, retomamos o autor, "o indivíduo por sua vez não é uma forma originária evoluindo no mundo como em um cenário exterior ou um conjunto de dados aos quais ele se contentaria em reagir: ele só se constitui ao se agenciar, ele só existe tomado de imediato em agenciamentos" (ZOURABICHVILI, 2004, p. 20).

Considerando uma concepção do desejo liberada da limitação de um fim, um fundamento fixo e objetivável, figurando sob uma negatividade, uma falta, como se efetua então a relação entre o desejo e o campo da lei tendo em vista o nexo entre instituição e as necessidades e tendências, entre o desejo, a lei e seu objeto? Destarte, que configuração podemos vislumbrar na relação entre desejo e autoridade? A demonstração dessa relação parece ser complexa. Deleuze ressalta que o alcance de tal complexidades encontra ressonâncias na psicanálise, de modo que, quando Lacan associa a lei ao desejo ele o faz subtraindo o recalque que a fundamenta, dado que "o objeto da lei e o objeto do desejo são um só, e se furtam ao mesmo tempo" (DELEUZE, 2009, 85), ou seja, é preciso constatar a ambivalência que conecta a dimensão do desejo ao regime da autoridade e da lei, considerando o fato de que ao mesmo tempo em que tais dimensões se ampliam, ocupando todas as esferas da vida, não encontrando limites em seu campo de experimentação, isso se dá, de forma angular e complementar, em função da perda do objeto do desejo e da lei. Fazendo um recuo, é preciso retomar o fato de que se na antiguidade a relação entre a Lei e a autoridade tem na figura de Antígona a força e contextualização materializadas no âmbito da Pólis, em Sócrates e Platão, tal relação evoca uma dimensão transcendente determinada pela ideia do Bem. Mas é na modernidade, precisamente em Kant, que se descortina um esvaziamento visto que o liame dar-se-á no âmbito da Lei, como forma pura.

No livro Sacher-Masoch Deleuze analisa a imagem clássica da autoridade e considera que a partir de Platão, a lei não é a instância primeira, não é o elemento fundador, mas reside como representação do Bem, demarcando uma dimensão lógica e transcendente. Na modernidade, precisamente em Kant, a lei não se fundamenta mais sob o domínio do bem, não se rege mais às expensas de um princípio supremo nem representa a elevação e hierarquia de valores morais. Por conseguinte, se a lei não se encontra mais subordinado à ideia do Bem, não é tutelada por um conteúdo, um domínio ou circunstância, em contrapartida, a relação entre o bem e a lei se efetua em função de uma dependência sendo o primeiro uma decorrência da segunda. A lei não se funda e não está mais ancorada num princípio superior e abstrato, mas em si mesma, ela se funda e passa a valer em si e por si, como pura forma da Lei. A 
autonomia do sujeito e as consequências assinaladas na revolução copernicana tornam-se decisivas à consolidação de um quadro reversões que, não apenas no âmbito do conhecimento, na relação sujeito e objeto, mas também no campo da razão prática será crucial para autonomia da lei.

Quando Kant (...) fala de "a" lei moral, a palavra "moral" designa somente a determinação daquilo que permanece absolutamente indeterminado: a lei moral é a representação de uma forma pura, independente de um conteúdo e de um objeto, de um domínio e de circunstâncias. A lei moral significa A Lei, a forma da lei, excluindo qualquer princípio superior capaz de fundá-la (DELEUZE, 2009, 83).

Para Deleuze, ao fazer da Lei um fundamento último, Kant concede ao pensamento moderno seu caráter principal, qual seja, o fato de que a lei se esquiva, se desvia de seu objeto, pois "o objeto da lei se furta essencialmente". A Lei se define, portanto, por sua pura Forma, desvinculada de conteúdo e matéria, desprovida de objeto e especificação uma vez que ela atua nos corpos, nas relações e na vida, de forma oculta, destituída de conteúdo e determinação; ela passa a designar uma região sombria, um campo de "errância em que todos somos culpados", imersos numa transgressão indefinida que se reveste de uma culpabilidade em vista do qual somos submetidos “à extrema precisão do castigo” (DELEUZE, 2009, 83-84). Kafka percorreu os meandros dessa errância e retratou a dimensão sinuosa dessa culpabilidade em suas obras e o castigo ao grau máximo, sem que se reconheça o significado da pena. Essa ampliação da culpa e o rigor da lei subverte a própria noção de tirania quando este não mais evoca uma anomia, mas emerge como efeito da aplicação da lei, e atua ancorado e legitimado pela lei.

É sob essa perspectiva que podemos pensar a relação entre o desejo, a lei, a autoridade. Para Deleuze, a lei encerra uma instância de usurpação do poder, "a lei, sob todas as suas formas (natural, moral, política), é a regra de uma natureza segunda, sempre ligada a exigências de conservação e usurpando a verdadeira soberania"; e o desejo encontra na lei a sua face mais perigosa quando se reveste de uma linha dura e busca na lei o respaldo necessário para se materializar, constituindo uma linha fascista.

O risco de se conjurar uma linha fascista é inerente às relações e maquinações do desejo na medida em que este se abriga nos estratos que visa ultrapassar. Como advertem Deleuze e Guattari,

Faz-se uma ruptura, traça-se uma linha de fuga, mas corre-se sempre o risco de reencontrar nela organizações que reestratificam o conjunto, formações que dão novamente o poder a um significante, atribuições que reconstituem um sujeito — tudo o que se quiser, desde as ressurgências edipianas até as concreções fascistas. Os grupos e os indivíduos contêm microfascismos sempre à espera de cristalização (DELEUZE/GUATTARI, 1995, 18-19).

Tal configuração se estabelece porque a linha de fuga carrega uma ambigüidade que a faz se converter em linha de abolição, de forma que, ela pode se revestir de formas autoritárias e usurpadoras podendo restituir modelos dominantes ou fascistas, e isso se determina, como salienta Zourabichvili, face ao perigo das reterritorializações do desejo $(2004,64)$. 


\section{REFERÊNCIAS}

DELEUZE, G. Instincts et institutions. Textes et documents philosophique. Paris: Ed. Hachette, 1955. Trad. bras. Instinto e instituições. In: As ilhas desertas: e outros textos. (Org) David Lapoujade. Tradução brasileira de Luiz Orlandi. São Paulo: Iluminuras, 2006. . Empirisme et subjectivité. Paris: PUF, 1953. [Ed. Bras.: Empirismo e subjetividade: ensaio sobre a natureza bumana segundo Hume . São Paulo : Ed. 34, 2001.] . As ilhas desertas: e outros textos. (Org) David Lapoujade. Tradução brasileira de Luiz Orlandi. São Paulo: Iluminuras, 2006. Sacher Masoch: o frio e o cruel. Rio de Janeiro: Zahar, 2009.

DELEUZE, G.; GUATTARI, F. Capitalisme et schizophrénie, t.1 : L'Anti-CEdipe. Paris : Minuit, 1972. [Ed. Bras. Trad. Luiz Orlandi. Anti -CEdipo: Capitalismo e esquizofrenia. São Paulo: Ed. 34, 2011, 1966.]. Capitalisme et schizophrénie, t.2 : Mille Plateaux. Paris : Minuit, 1980. [Ed. Bras. Trad. Luiz Orlandi. Mil Platôs: Capitalismo e esquizofrenia. São Paulo: Ed. 34, 5 vols, 1995-1997.]

DELEUZE, G.; PARNET, C. L'abécédaire de Gilles Deleuz̨e. Paris: Éditions Montparnasse, 1996 (Vidéo). Entrevista à Claire Parnet concedida em 1988, filmada e dirigida por Pierre-André Boutang, e transmitida em série televisiva a partir de novembro de 1995, pela TV-ARTE. A tradução brasileira das legendas em português foi feita por Tomaz Tadeu. Texto traduzido em português disponível em: http://escolanomade.org/wp-content/downloads/deleuze-o-abecedario.pdf Acesso em 19/12/2019. . Dialogues (en collaboration avec Claire Parnet). Paris : Flammarion, 1997. [Ed. Bras. Diálogos. São Paulo : Escuta, 1998.]

SIBERTIN BLANC, G. Deleuze et l'Anti-Oedipe: la production du desir. Paris: Puf, 2010. ZOURABICHVILI, F. Deleuze - une philosophie de l'événement. In: ZOURABICHVILI, F.; SAUVAGNARGUES, A.; MARRATI, P. La philosophie de Deleure, Paris: PUF, 2004. 